\title{
Drought Analysis Using Standardized Precipitation Index (SPI): A Case Study in Jaffna Peninsula in Sri Lanka
}

\author{
T. Sellathurai ${ }^{*}$, K. Venugoban ${ }^{2}$, S.S. Sivakumar ${ }^{3}$ and T. Mikunthan ${ }^{4}$ \\ ${ }^{1}$ Faculty of Graduate Studies, University of Jaffna, Sri Lanka. \\ ${ }^{2}$ Computer Unit, Faculty of Agriculture, University of Jaffna, Sri Lanka. \\ ${ }^{3}$ Department of Civil Engineering, Faculty of Engineering, University of Jaffna, Sri Lanka. \\ ${ }^{4}$ Department of Agricultural Engineering, Faculty of Agriculture, University of Jaffna, Sri Lanka.
}

\section{ARTICLE INFO}

\section{Article history:}

Received: 28 August 2020

Revised version received: 23 January 2021

Accepted: 31 January 2021

Available online: 30 July 2021

\section{Keywords:}

Drought

Jaffna,

SPI.

\section{Citation:}

Sellathurai, T., Venugoban, K., Sivakumar, S.S. and Mikunthan, T. (2021). Drought analysis using Standardized Precipitation Index (SPI): A case study in Jaffna peninsula in Sri Lanka. Tropical Agricultural Research, 32(3): 338-348.

DOI: http://doi.org/10.4038/tar.v32i3.8497

Sellathurai, T.

https://orcid.org/0000-0001-7576-8581

\section{ABSTRACT}

The drought analysis is a prime component in the preparedness of drought and the water resources management. The status of drought in Jaffna was investigated using standardized precipitation index (SPI) at 1, 3, 6, 9 and 12 months' time scale using monthly rainfall (1985 - 2019) data of Thirunelvelli meteorological station. Results revealed that the annual rainfall has no trend in long term but there were seasonal and short term variations found. Around $29 \%$ of study period was under dry condition. October, November, December and January months can be recorded as rainy months. Higher number of wet events was recorded during January to March. The second inter monsoon and northeast monsoon received high amount of rainfall. The number of wet event increases with years in Yala and vice versa during Maha. That is there was some variation in the onset of rainfall in this region. Nine hydrological years 198889, 1990-91, 1994-95, 2000-01, 2004-05, 2009-10, 2013-14, 2016-17 and 2018-19 as dry years and 1985-86, 1993-94, 200102, 2003-04, 2005-06, 2007-08 and 2014-15 have been identified as wet years. The result obtained through this time scale much with the country's rainfall pattern. Therefore, SPI analysis confirms the historical drought situations over the country by using rainfall as an input.

\footnotetext{
*Corresponding author: thusyanthi_sella@yahoo.com
} 


\section{INTRODUCTION}

Agriculture sector is very sensitive to the climatic condition. The variation in the climatic conditions; rainfall and temperature directly affect the cultivation and harvesting. Drought is one of the major environmental disasters, and occurs in almost all climatic zones and it influences the environment and economy of the country (Moumita and Sujata, 2013). Sujitha and Shanmugasundaram, (2017) indicated that more than one half of the earth is susceptible to drought each year. Drought originates from a shortage of precipitation, high evapotranspiration and overexploitation of water resources or combination of all these factors (Bhuiyan, 2004).

As indicated by Zagar et al, (2011), drought can be generally defined as the extreme persistence of precipitation deficit over a specific region for a specific period. The drought can be explained by different ways; meteorological drought, hydrological drought, agricultural drought and socio economic drought. Asefjahet al, (2014) explained the before mentioned droughts as less amount of precipitation from the normal precipitation over a specific period of time, the shortage in surface and subsurface water resources, the lack of soil moisture required for the development of a crop at a particular period and the failure of a water resources to meet the water demand respectively.

In addition to the deficiency created by means of amount, intensity and frequency of precipitation, the low relative humidity result from high temperature, high winds, greater sunshine and less cloud cover leads to increased evapotranspiration. If this type of condition exists for a certain period leads to the reduction in soil moisture and exposes the plant to the water stress condition which lead to the reduction in biomass and yield. Also, it will influence the hydrological condition of the area by reducing stream flow, inflow to reservoirs, lakes and ponds and reduced wetlands. Finally, it impacts the economy, social and environmental conditions (Zagar et al, (2011).

Jaffna peninsula solely depends on the groundwater to meet its water needs by means of four major aquifers namely; Vallikamum, vadamaradchi, Thenmaradchi and Kayts. The rainwater received during the monsoonal period stored in the aquifers as groundwater. This water meets the water demand of different stakeholders; agriculture, industry, domestic etc.
The analysis of drought in this region will help to effective and efficient utilization of the groundwater as well as to avoid the economic loss in the field crop cultivation. The understanding regarding the drought is very essential since in long term it will affect the agriculture as well as the hydrology of the region. According to Smakhtin and Hughes, (2004) SPI has been used in more applications in South West Asia than other drought indices due to its limited data requirement, that is it is based just on precipitation, flexibility and simplicity of calculations. The multiple time scales; $1,3,6,9$ and 12 months in SPI explain different phenomenon as indicated in the Table 1 and it can be utilized for different applications. It has been used in recent drought related studies for evaluating climate change effect on agriculture, hydrology, water resources and ecosystem (Capra et al, 2012). The positive value indicates the wet condition and the negative value indicates the dry condition. Therefore, an analysis was done to investigate observed drought in the historical rainfall records using SPI with different time scale.

\section{METHODOLOGY}

\section{Study area}

The Jaffna peninsula located at Northern part of Sri Lanka and covers the area of $1025 \mathrm{~km}^{2}$. The four rainy seasons of Sri Lanka; first inter-monsoon, south-west monsoon, second inter-monsoon and the north-east monsoon can be observed in this region but with some variation in the starting and ending time.

\section{Data collection and analysis}

The rainfall data for the period of 1985 to 2019 was collected from Thirunelvelli meteorological station and used to analyses the drought. There are several techniques used to monitor drought in a region or worldwide (WMO and GWP, 2016). In this study standard precipitation index (SPI) used to analyses the drought (McKee et al. 1993). It is a simple index utilizes only precipitation data for a long period of time with the minimum of 30 years to describe drought conditions and

it is important for a range of meteorological, hydrological, and agricultural application.

Analysis was done in different time sequence, and time duration October to September was used as the hydrological year (SPI 12), October to June and July to March were used as 9 - month time scale 
(SPI 9) and October to March and April to September were used as 6 - month time scale (SPI 6) as these periods are cropping seasons of Maha and Yala, respectively, in Sri Lanka (Abeysingha and Rajapaksha, 2020). October to December, January to March, April to June, and July to September were used as 3 - month time scale (SPI 3 ). Calculated SPI values were compared with the SPI classification values for dryness or wetness category to indicate the status of the drought (Table 1). The drought frequency was calculated using SPI. For this frequency calculation, the drought was defined as SPI < 0 (Liu et al., 2017).

Table 1: Dryness or wetness category according to SPI value.

Class

\begin{tabular}{ll}
\hline Extreme wet & $>2$ \\
Very wet & 1.5 to 2 \\
Moderate wet & 1.0 to 1.49 \\
Near normal & 0.99 to -0.99 \\
Moderate drought & -1 to -1.49 \\
Severe drought & -1.5 to -1.99 \\
Extreme drought & $<-2.0$ \\
\hline
\end{tabular}

Source: Jaber, 2014

\section{Data processing}

The Figure 1 shows the step by step process in the SPI calculation. First, the shape parameter $(\alpha)$ and the scale parameter $(\beta)$ for the Gamma distribution for each time of interest were estimated. These parameters can be determined using following equation which is determine by Thom (1966) based on maximum likelihood method and followed by Sujitha and Shanmugasundaram (2017).

$A=\ln (\bar{x})-\frac{\sum \ln (\bar{x})}{n}$,

$\alpha=\frac{1}{4 A}\left(1+\sqrt{\left(1+\frac{4 A}{3}\right)}\right)$ and

$\beta=\frac{\bar{x}}{\alpha}$

(Eq 1)

Where, $\mathrm{n}$ is the number of rainfall measurements, and $\bar{X}$ is the mean of observed rainfall $\mathrm{x}$ (amount of precipitation over the consecutive months in millimeter).

The gamma distribution is defined by its frequency or probability function.

$g(x)=\frac{1}{\beta^{\alpha} \tau(\alpha)} x^{\alpha-1} e^{\frac{-x_{k}}{\beta}}$
The estimated parameters are then used for calculating cumulative probability distribution for a specific precipitation event, which has been observed on a defined time scale (McKee,1993).

$G\left(x_{k}\right)=\int_{0}^{x_{k}} g\left(x_{k}\right) d x_{k}=\frac{1}{\beta^{\alpha} \tau(\alpha)} \int_{0}^{x_{k}} x^{\alpha-1} e^{\frac{-x_{k}}{\beta}} d x_{k}$

Where, $\mathrm{k}$ is the selected time scale in months and $\tau$ is the Gamma function. Letting $t=x / \beta$, this equation becomes the incomplete gamma function.

$G\left(x_{k}\right)=\frac{1}{\tau(\alpha)} \int_{0}^{x_{k}} t^{\alpha-1} e^{-t} d x_{k}$

Due to undefined gamma function for $\mathrm{x}_{\mathrm{k}}=0$, then the value of $G\left(x_{k}\right)$ becomes

$H x_{k}=q+(1-q) \cdot \mathrm{G}\left(x_{k}\right)$

Noted that $q$ is the probability of zero rainfall and $\mathrm{H}(\mathrm{x})$ which refers to cumulative probability is standardized wherewith to obtain the SPI value.

Lastly, to finish the calculation of SPI value, approximate conversion by Thorn (1966) is believed to use. The number of zeros rainfall data is symbolized with $\mathrm{m}$, and then the function of $\mathrm{q}$ could be estimated with $\mathrm{m} / \mathrm{n}$. The cumulative probability is then transformed into a normal standard random variable $\mathrm{Z}$, with an average value zero and a variation of 1 . The value obtained for $\mathrm{Z}$ is the SPI value. Normal standard value of random variable $\mathrm{Z}$ or SPI is accessible by using the approximation according to Abramowitz and Stegun (1964) with the equation 6 with two conditions.

Condition 1: $0<\mathrm{H}(\mathrm{x}) \leq 0.5$

$Z=S P I=-\left(t-\frac{C_{0}+C_{1} t+C_{2} t^{2}}{1+d_{1}+d_{2} t^{2}+d_{3} t^{3}}\right)$

Where, $t=\left(\ln \sqrt{\left(\frac{1}{\left(\left(H x_{k}\right)^{2}\right)}\right)}\right)$

Condition 2: $0<\mathrm{H}(\mathrm{x}) \leq 1.0$

$Z=S P I=-\left(t-\frac{C_{0}+C_{1} t+C_{2} t^{2}}{1+d_{1}+d_{2} t^{2}+d_{3} t^{3}}\right)$

Where, $t=\left(\ln \sqrt{\left(\frac{1}{\left(\left(1-H x_{k}\right)^{2}\right)}\right)}\right)$

$\mathrm{C}_{0}=2.515517, \mathrm{C}_{1}=0.802853, \mathrm{C}_{2}=0.010328, \mathrm{~d}_{1}=$ $1.432788, \mathrm{~d}_{2}=0.189269, \mathrm{~d}_{3}=0.001308$. 
Table 2: The phenomena reflected by different time scale in SPI and its application.

\begin{tabular}{|c|c|c|}
\hline SPI duration & Phenomena reflected & Application \\
\hline 1 month & Short-term condition & $\begin{array}{l}\text { Short-term soil moisture and crop stress } \\
\text { (especially during the growing season) }\end{array}$ \\
\hline 3 months & $\begin{array}{l}\text { Short- and medium-term moisture } \\
\text { condition }\end{array}$ & A seasonal estimation of precipitation \\
\hline 6 months & Medium-term trend in soil moisture & $\begin{array}{l}\text { Potential for effectively showing the } \\
\text { precipitation over distinct season }\end{array}$ \\
\hline 9 months & $\begin{array}{l}\text { Precipitation patterns over a } \\
\text { medium time scale }\end{array}$ & $\begin{array}{l}\text { If SPI } 9<-1.5 \text { then it is a good indication that } \\
\text { substantial impacts can occur in agriculture and } \\
\text { possibly other sectors }\end{array}$ \\
\hline 12 months & Long term precipitation patterns & $\begin{array}{l}\text { Possibly link with stream flows, reservoir levels } \\
\text { and groundwater levels }\end{array}$ \\
\hline
\end{tabular}

Source: Pramudya and Onishi, 2018

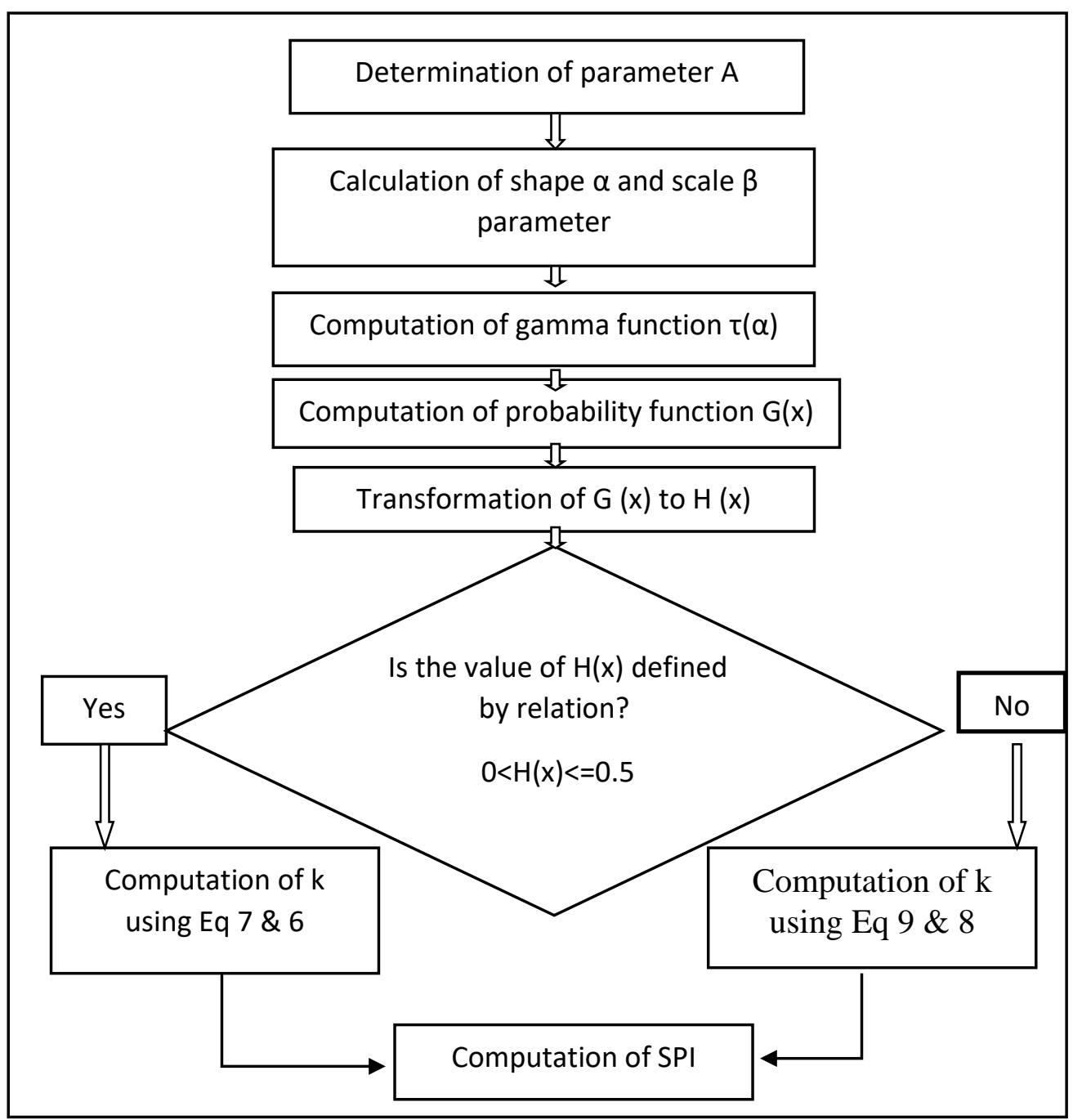

Figure 1: The steps in SPI calculation 


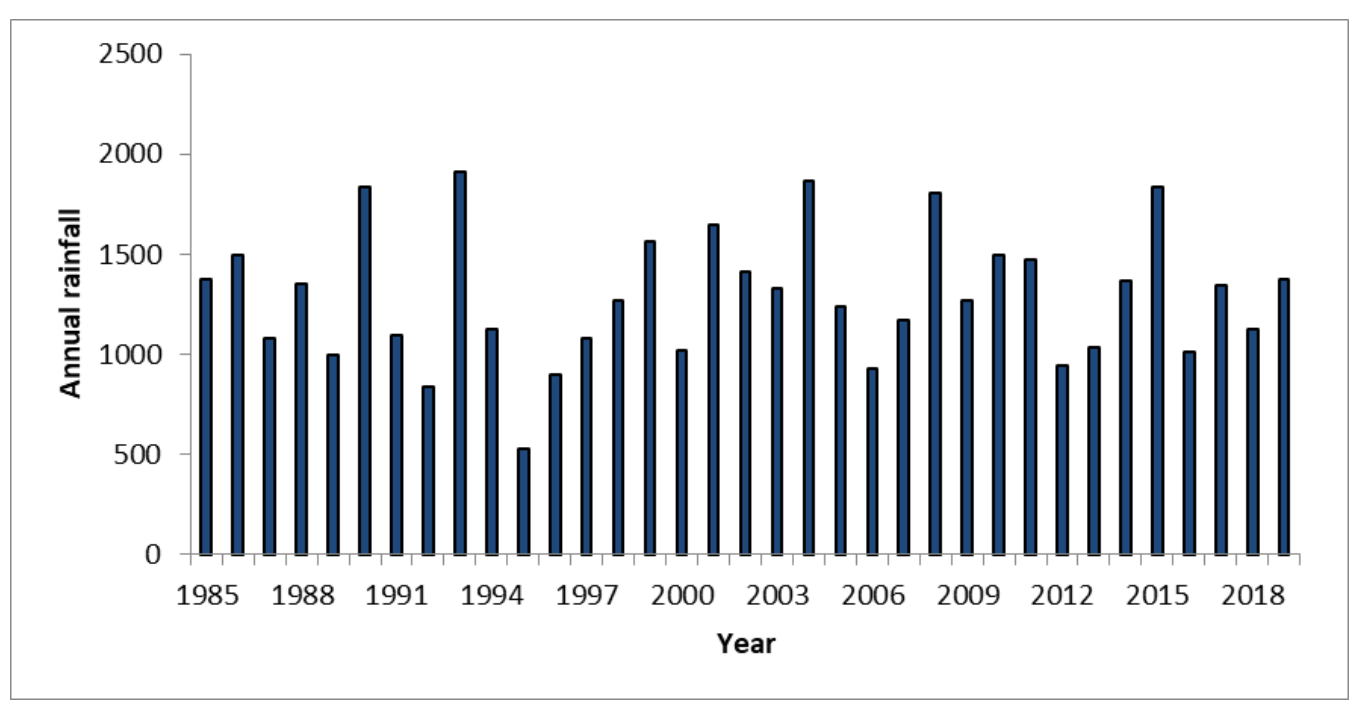

Figure 2: The rainfall data for the period of 1985-2019.

Table 3: Drought and wet occurrences.

\begin{tabular}{llllllll}
\hline \multirow{2}{*}{ Class } & \multirow{2}{*}{ SPI value* $^{*}$} & \multicolumn{7}{c}{ Percentage in category (\%) } \\
\cline { 3 - 7 } & & SND $^{\mathbf{a}}$ & SPI 1 & SPI 3 & SPI 6 & SPI 9 & SPI 12 \\
\hline Extreme wet & $>2$ & 2.3 & 1.90 & 0.72 & 0.24 & 0.49 & 0.00 \\
Very wet & 1.5 to 2 & 4.4 & 4.05 & 5.50 & 2.40 & 5.35 & 5.11 \\
Moderate wet & 1.0 to 1.49 & 9.2 & 9.29 & 9.57 & 7.69 & 6.08 & 7.54 \\
Near normal & 0.99 to -0.99 & 68.2 & 73.10 & 68.90 & 78.85 & 74.94 & 74.45 \\
Moderate drought & -1 to -1.49 & 9.2 & 8.81 & 9.33 & 6.97 & 8.76 & 8.03 \\
Severe drought & -1.5 to -1.99 & 4.4 & 2.86 & 4.78 & 2.16 & 3.41 & 3.16 \\
Extreme drought & $<-2.0$ & 2.3 & 0.00 & 1.20 & 1.68 & 0.97 & 1.70 \\
\hline
\end{tabular}

*SPI value adapted from Jaber, 2014, a - Standard Normal Distribution (SND)

\section{Input data for SPI calculation}

The monthly total rainfall data collected from the Thirunelwelli meteorological station for the period of 1985-2019 was used to analyze the drought event in the study area. The annual rainfall data was shown in Figure 2 for the time duration from 1985 to 2019. To maintain the continuity in the time series, the missing data for the period of 1996 and 1997 was estimated by average of the previous and the following year rainfall measurements for the same month.

\section{RESULTS AND DISCUSSION}

The analysis shows the drought and wet condition at $1,3,6,9$ and 12 month time scale for Jaffna peninsula, Sri Lanka for the period of 1985-2019 (35 years). Here, the SPI values are termed correspondingly as SPI 1, SPI 3, SPI 6, SPI 9 and SPI 12.
The SPI classification about dry and wet events and the percentage available in each category in the time scales are shown in Table 3. The SPI values are divided here arbitrarily into categories ranging from extreme wet (relative to the mean and standard deviation of the data) to extreme drought. The percentage available in the theoretical standard normal distribution is also presented in the table for a comparison with the categories for the data of Jaffna. With increase in the time scale less amount of extreme wet events were recorded. It was notice as vice versa for very wet event except SPI 6. Nine month scale shows less amount of moderately wet condition; implies considerable impact on agriculture and other sectors (Table 2). Moderate drought and severe drought conditions were highly observed in SPI 3 . The result shows the monthly rainfall event highly fluctuating and the value is higher than the normal distribution probability of the rainfall. 
The temporal behaviour of the SPI value is presented in the Figure 3. The number of events for the drought intensities was highly variable in SPI 1 and SPI 3. That is on a small scale the fluctuation of the intensities between less than -1 and greater than 1 is high. This variation is due to a seasonal component found in the rainfall data (Jaber, 2014). However, on a larger scale such as SPI 9 and SPI 12, the drought becomes less frequent. Out of 420 months analysed the 205 months fall under category of normal rainfall, 120 months under dry condition and rest of them under wet condition. The maximum SPI value $(-4.79)$ recorded in the year 1995 in six month timescale. For 1, 3, 9 and 12 months' time scale SPI value is maximum in the year 1995 (-3.90), $1995(-3.90), 1992(-3.46)$ and
$1995(-3.00)$ respectively. These results much with the records of the subsidy and support provided to the farmers for flood and drought events. It is also noted that nearly $29 \%$ of the study period is under the influence of drought and 50\% under normal condition. On the other hand, for the all the time series shown in Figure 3, there is no long-term trend component recognized. The slope and interception value of the liner regression of the observations were nearly zero.

This result would be useful to explain the phenomenon related to severity or frequency of drought in this location (Jaber, 2014).
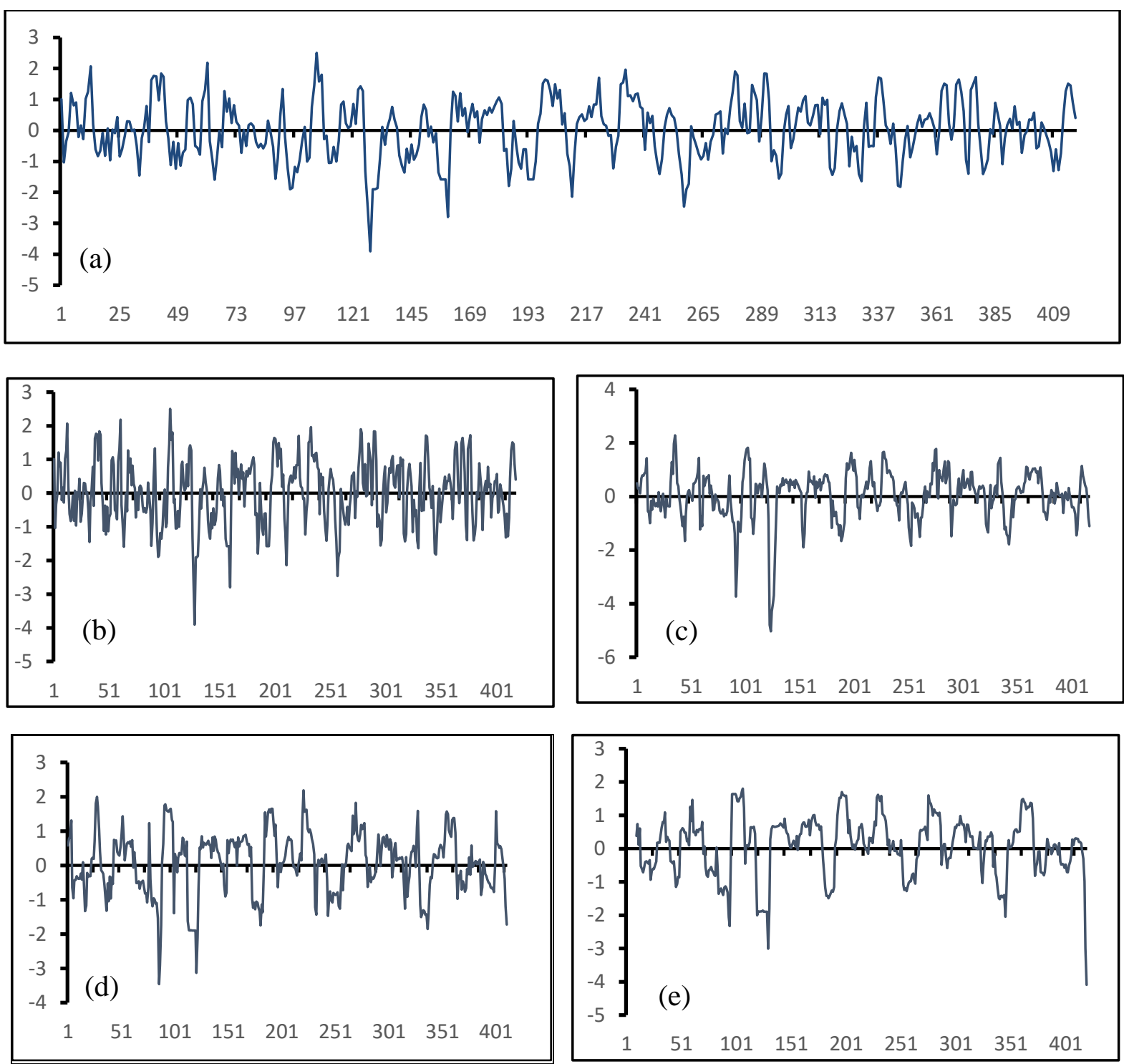

Figure 3: SPI for the rainfall data for the time scales of $1,3,6,9$ and 12 (a, b, c, $d$ and e). The X axis shows the time (month) and Y axis shows the SPI values. 

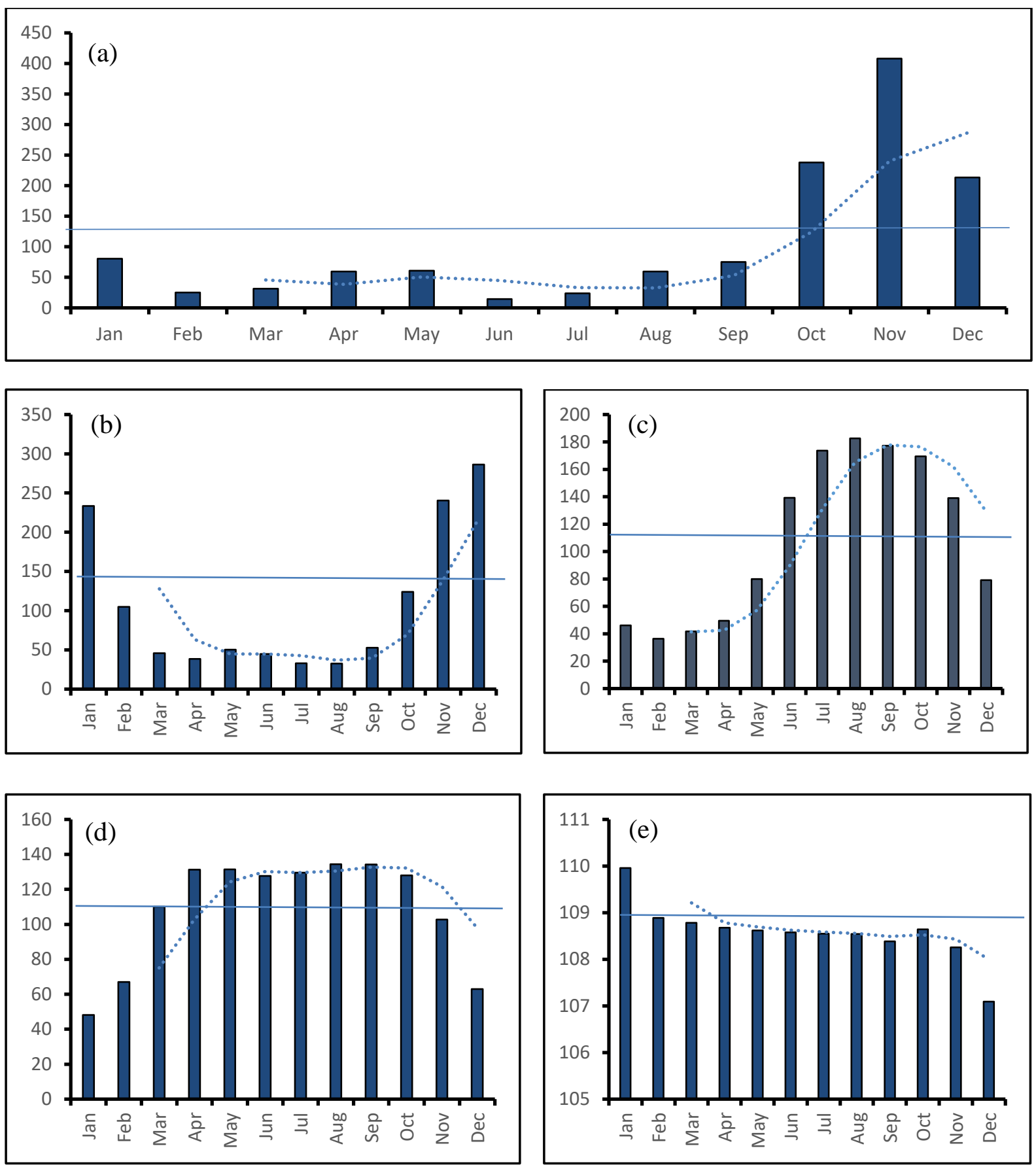

Figure 4: The average rainfall for the time scales of $1,3,6,9$ and 12 (a, b, c, $d$ and $e)$. The $X$ axis shows the time (month) and $Y$ axis shows the average rainfall (---- 3 year moving average, rainfall of Jaffna).

It also noted that the four seasons; north east monsoon, first inter monsoon, south west monsoon and second inter monsoons are clear in this district (Figure 4) and it is possible to say wet and dry months. As it can be seen in Figure 4, the rainy months in Jaffna are October, November, December and January (Figure 4 (a)) and most of the month receiving less than $100 \mathrm{~mm}$ rainfall in average and it implies the short-term soil moisture stress and crop stress during the growing season. To overcome this farmers rely on irrigation water. With increase in the time scale the distribution of average rainfall become normal. Means the distribution follows a bell-shape and become liner in SPI 12. Therefore, in this region the annual rainfall have no trend in long term but the seasonal and short term variations were recorded. These result much with Jayawardene et al., (2005) reported that annual rainfall calculated using monthly average did not show consistent increases 
or decreases in Sri Lanka. The second inter monsoon period October and November receive considerably large amount of rainfall. The seasonality of the rainfall can be explained using SPI 3 (Table 2).

The second inter monsoon and North east monsoon period receive high amount of rainfall and the south west monsoon period May to September received less amount of rainfall (Figure 4 (b)). The July month is the hottest month in this region. These finding agree much with Piratheeparajah (2016).

The SPI 3 divided into January to March, April to June, July to September and October to December (Figure 5). The results show, higher number of wet events were recorded during January to March, where the north east monsoon period covered. It followed by October to December (second inter monsoon period), July to September (south west monsoon period) and April to June (first inter monsoon period). During July to September higher number of moderately and severe drought conditions recorded. Previous study also reveals that, during the south west monsoon period, the amount of rainfall received is comparatively less than during other seasons, because Northern region is located opposite to the direction of the moisture laden South West Monsoon wind (Piratheeparajah, 2016).

The occurrence of drought events during Maha and Yala can be explained by using SPI 6 since it covers the period of October to March and April to September. The number of years showing moderately dry condition $(<-1)$ and wet condition $(>1)$ is high in Yala (Figure 6). More frequent drought event recorded during Yala. Also the extreme cases of rainfall recorded in Yala than in Maha in this region. The year $1992(-3.73)$ and 1995 (-3.69) showed the extreme dry condition during Yala and 1995 (-4.79) during Maha. During the hydrological year 1987-88, the extremely wet event recoded. The number of wet event increases with years in April to September period and vice versa during October to March period. Therefore, it can be say there were some variation in the onset of rainfall in this region.

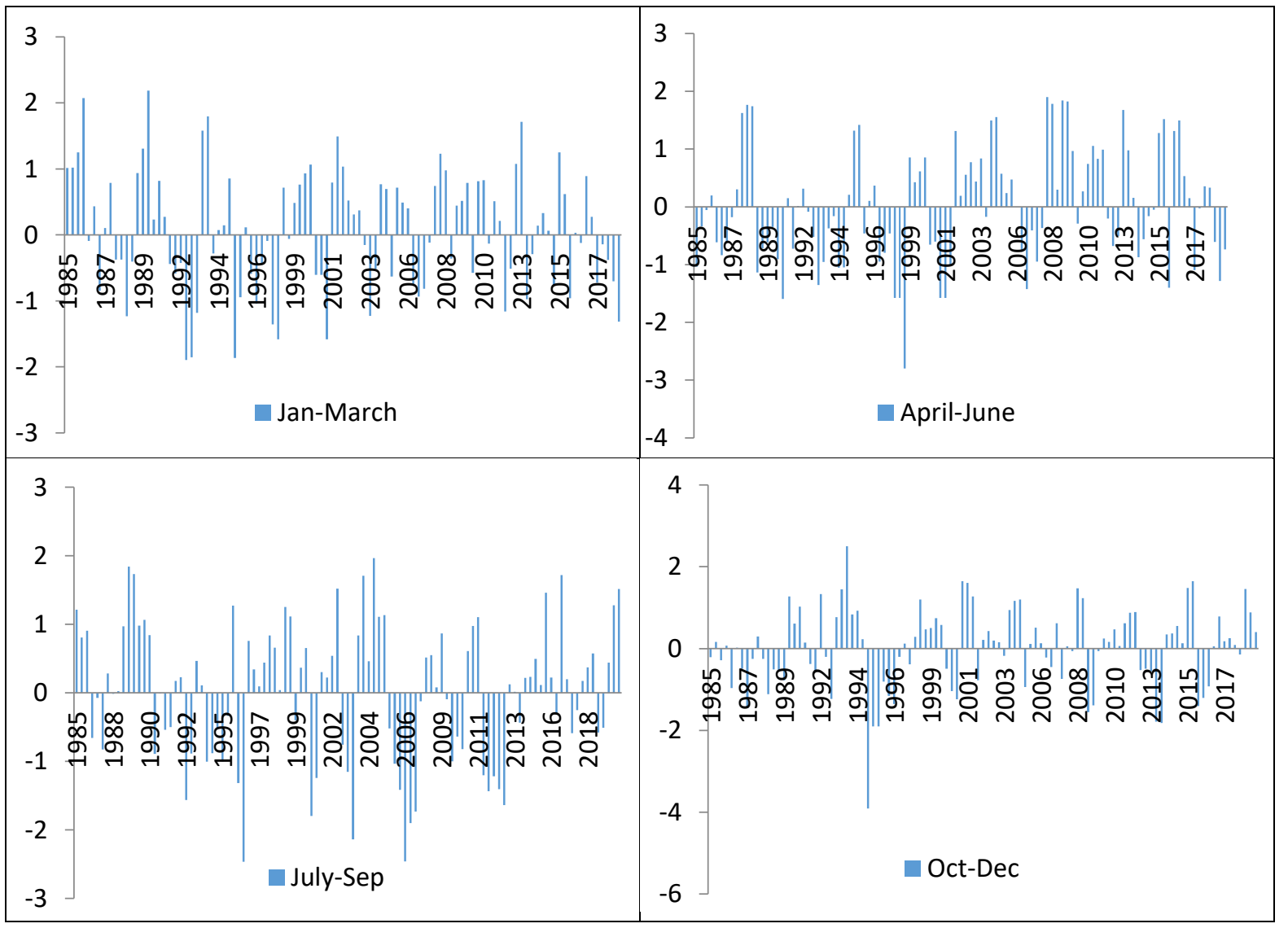

Figure 5: The SPI value for 3 months scale. The $X$ axis show hydrological year and Y axis show SPI 3 values. 


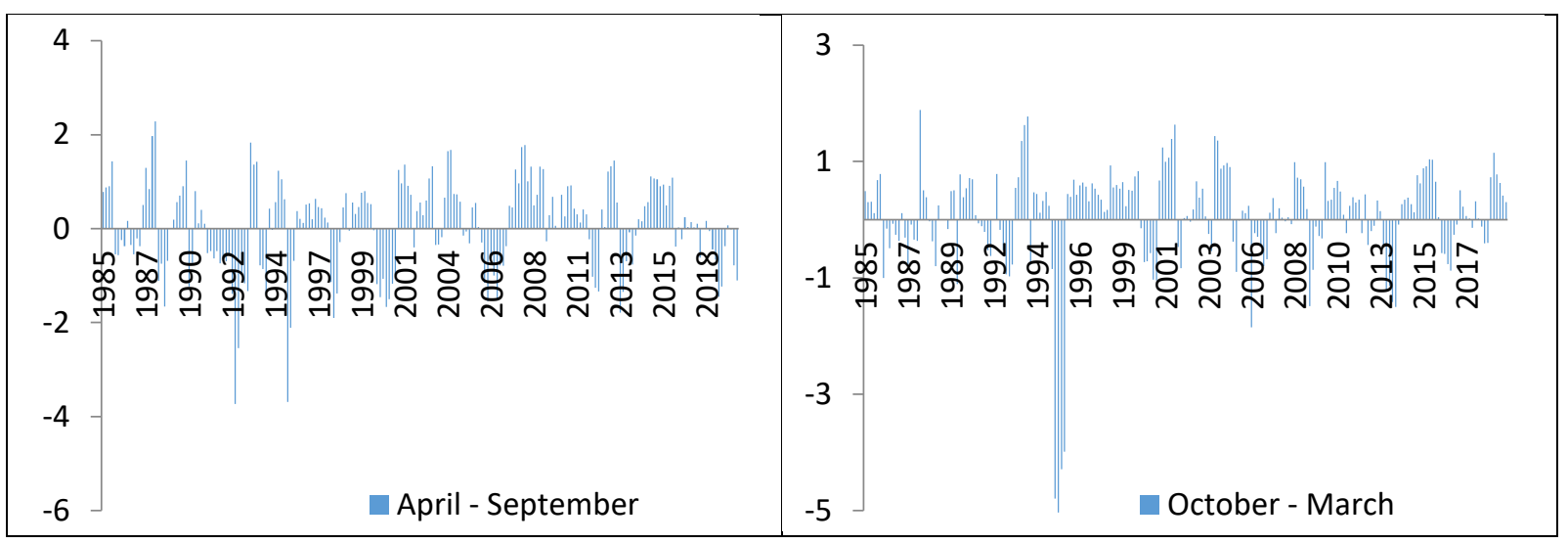

Figure 6: The SPI for Yala and Maha season. The X axis show hydrological year and Y axis show SPI 6 values.

Table 4: The summary of SPI classes for the period of 1985-2019.

\begin{tabular}{|c|c|c|c|c|c|}
\hline Year & SPI 1 & SPI 3 & SPI 6 & SPI 9 & SPI 12 \\
\hline 1985 & Very wet & Extremely wet & Extremely wet & Extremely wet & Moderately wet \\
\hline 1986 & Extremely wet & Near normal & Extremely dry & Extremely dry & Extremely dry \\
\hline 1987 & Moderately dry & Extremely dry & Moderately dry & Moderately dry & Extremely wet \\
\hline 1988 & Extremely wet & Extremely wet & Extremely wet & Near normal & Extremely dry \\
\hline 1989 & Moderately dry & Extremely dry & Extremely wet & Extremely wet & Extremely wet \\
\hline 1990 & Very wet & Extremely wet & Extremely wet & Extremely wet & Extremely wet \\
\hline 1991 & Moderately wet & Near normal & Extremely dry & Extremely dry & Extremely dry \\
\hline 1992 & Extremely dry & Extremely dry & Extremely dry & Extremely dry & Extremely dry \\
\hline 1993 & Near normal & Extremely dry & Extremely wet & Extremely wet & Extremely wet \\
\hline 1994 & Near normal & Near normal & Moderately dry & Extremely wet & Near normal \\
\hline 1995 & Extremely dry & Extremely dry & Extremely dry & Extremely dry & Extremely dry \\
\hline 1996 & Near normal & Extremely dry & Extremely wet & Extremely wet & Extremely wet \\
\hline 1997 & Near normal & Extremely dry & Extremely wet & Extremely wet & Extremely wet \\
\hline 1998 & Extremely dry & Extremely dry & Near normal & Extremely wet & Extremely wet \\
\hline 1999 & Extremely wet & Extremely wet & Extremely wet & Extremely wet & Extremely wet \\
\hline 2000 & Near normal & Extremely dry & Extremely dry & Extremely dry & Extremely dry \\
\hline 2001 & Moderately wet & Near normal & Extremely wet & Extremely wet & Extremely wet \\
\hline 2002 & Very wet & Moderately wet & Moderately wet & Extremely wet & Extremely wet \\
\hline 2003 & Extremely wet & Extremely wet & Extremely wet & Extremely wet & Extremely wet \\
\hline 2004 & Extremely wet & Extremely wet & Extremely wet & Extremely wet & Extremely wet \\
\hline 2005 & Extremely dry & Moderately dry & Near normal & Extremely dry & Near normal \\
\hline 2006 & Extremely dry & Extremely dry & Extremely dry & Extremely dry & Extremely dry \\
\hline 2007 & Moderately wet & Extremely dry & Near normal & Extremely wet & Extremely wet \\
\hline 2008 & Extremely wet & Extremely wet & Extremely wet & Extremely wet & Extremely wet \\
\hline 2009 & Near normal & Near normal & Moderately wet & Moderately dry & Near normal \\
\hline 2010 & Extremely wet & Extremely wet & Extremely wet & Extremely wet & Extremely wet \\
\hline 2011 & Near normal & Extremely wet & Extremely wet & Moderately wet & Very wet \\
\hline 2012 & Extremely dry & Extremely dry & Extremely dry & Near normal & Near normal \\
\hline 2013 & Very wet & Near normal & Extremely dry & Extremely dry & Extremely dry \\
\hline 2014 & Moderately wet & Near normal & Moderately wet & Extremely wet & Extremely wet \\
\hline 2015 & Extremely wet & Extremely wet & Extremely wet & Extremely wet & Extremely wet \\
\hline 2016 & Extremely dry & Near normal & Near normal & Extremely dry & Extremely dry \\
\hline 2017 & Extremely wet & Very wet & Near normal & Near normal & Near normal \\
\hline 2018 & Near normal & Near normal & Extremely dry & Extremely dry & Extremely dry \\
\hline 2019 & Very wet & Near normal & Near normal & Moderately wet & Extremely dry \\
\hline
\end{tabular}


If the SPI values are below -2.00 , then those events are referred to be extreme drought events (Table 2). Accordingly, the year 1991, 1992, 1995, 2000, 2006, 2012, 2013, 2016 and 2018 can be denoted as extremely dry years (Table 4). Analyzing these extreme drought events is of great importance for the design and management of water resources systems ((Abeysingha and Rajapaksha, 2020).

The annual rainfall subjected to SPI analysis and nine hydrological years 1988-89, 1990-91, 199495, 2000-01, 2004-05, 2009-10, 2013-14, 2016-17 and 2018-19 have been identified as dry years where more than $80 \%$ of the periods under dry condition. Among them, the 1994-95, 2004-05 and 2013-14 hydrological years showed maximum number of drought event (100\%) than others.

Previous studies showed, 1988-89, 2000-01, 201314 and 2016-17 as drought years in Sri Lanka (Abeysingha and Rajapaksha, 2020). According to the impact of disasters in Sri Lanka (2016) reported severe drought in 2001, 2004 and 2014. Therefore, SPI analysis confirms these historical drought situations over the country through SPI by using rainfall as an input. The hydrological years 1985-86, 1993-94, 2001-02, 2003-04, 2005-06, 2007-08 and 2014-15 have been identified as wet years.

\section{CONCLUSIONS}

From this study it can be concluded that the annual rainfall has no trend in long term but there were

\section{REFERENCES}

Abeysingha, N.S. and Rajapaksha, U.R.L.N. (2020). SPI-based spatiotemporal drought over Sri Lanka. Advances in Meteorology, vol. 2020, Article ID 9753279, https://doi.org/10.1155/2020/9753279

Abramowitz, M. and Stegun, I. (1964). A Handbook of Mathematical Functions: With Formulas, Graphs, and Mathematical Tables. Courier Corporation, p.55.

Asefjaha , B., Faniana , F., Feizia , Z., Abolhasania , A., Paktinatb , H.,Naghiloua, M., MolaeiAtanic , A., Asadollahia, M. , Babakhania , M. , Kouroshni A and SalehiaF. (2014). Meteorological drought monitoring using several drought indices (case study: Salt Lake Basin in Iran). Desert. 19(2), 155-165. seasonal and short term variations found. The SPI can used to explain the intensity and severity of rainfall and seasonal rainfall pattern in this region. The short term moisture stress and crop stress was well expressed by SPI 1 and the SPI 3 and SPI 6 can used to express the seasonal rainfall pattern. October, November, December and January months can be recorded as rainy months. The second inter monsoon and North east monsoon period receive high amount of rainfall and the south west monsoon period May to September received less amount of rainfall. Higher number of wet events was recorded during January to March, where the north east monsoon period was covered. The number of wet event increases with years in April to September period and vice versa during October to March period. Therefore, it can be say there were some variation in the onset of rainfall in this region. nine hydrological years 1988-89, 199091, 1994-95, 2000-01, 2004-05, 2009-10, 2013-14, 2016-17 and 2018-19 as dry years and 1985-86, 1993-94, 2001-02, 2003-04, 2005-06, 2007-08 and 2014-15 have been identified as wet years. The result obtained through this time scale much with the country's rainfall pattern. Therefore, SPI analysis confirms the historical drought situations over the country by using rainfall as an input.

\section{ACKNOWLEDGMENT}

The authors are grateful to the Department of meteorology for providing the rainfall data. This work was financially supported by WaSo project of University of Jaffna.

Bhuiyan, C. (2004). Various Drought Indices for Monitoring Drought Condition in Aravalli Terrain of India. https://www.researchgate.net/publication/22 9042188.

Capra, A. and Scicolone, B. (2012). Spatiotemporal variability of drought on a short-medium time scale in the Calabria Region (Southern Italy). Theoretical and Applied Climatology. 3, 471488.

Consortium of Humanitarian Agencies (CHA). (2016). Impact of Disasters in Sri Lanka. The Consortium of Humanitarian Agencies (CHA), Colombo, Sri Lanka.

Jaber, A. (2014). Drought analysis of Kuwait using standard precipitation index. The Scientific world 
journal.http://dx.doi.org/10.11155/2014/45/ 841

Jayawardene, H.K.W.I, Sonnadara, D.U.J. and Jayewardene, D.R. (2005). Trends of rainfall in Sri Lanka over the last century, Sri Lankan Journal of Physics. 6, 7-17.

Liu, B. Yan, Z. Sha, J. and Li, S. (2017). Drought evolution due to climate change and links to precipitation intensity in the haihe river basin, Water. 9(11), 878.

McKee T.B, Doesken N.J, Kleist J. (1993). Drought monitoring with multiple time scales. Paper presented at the Preprints, Eighth Conference on Applied Climatology, Anaheim, California.

Moumita, P. and Sujitha, B. (2013). Analysis of Meteorological Drought Using Standardized Precipitation Index - A Case Study of Puruliya District, West Bengal, India. International Journal of Environmental and Ecological Engineering. 7, 167-174.

Piratheeparajah, N. (2016). Pattern of Spatial and Temporal Variations of Rainfall in the Northern Province of Sri Lanka, 1972 - 2014. Indian Journal of Spatial Science. 7, 1-6.

Pramudya, Y and Onishi, T. (2018). Assessment of the Standardized Precipitation Index (SPI) in Tegal City, Central Java, Indonesia. IOP Conf.
Series: Earth and Environmental Science 129, doi :10.1088/1755-1315/129/1/012019

Smakhtin, V.U. and Hughes, D.A. (2004). Review, automated estimation and analyses of drought indices in South Asia. Working Paper 83. International Water Management Institute, Colombo, Sri Lanka

Sujitha, E and Shanmugasundaram, K. (2017). Analysis of dry/wet conditions using the Standardized Precipitation Index and its potential usefulness for drought /flood monitoring in the regions of Trichy. Journal of Pharmacognosy and Phytochemistry. 6(4), 452457.

Thom, H.C.S. (1966). Some methods of climatological analysis. World Meteorological Organization, Technical Note No. 81, WMO-No199, Geneva, Switzerland.

World Meteorological Organization (WMO) and Global Water Partnership (GWP), (2016). Handbook of Drought Indicators and Indices (M. Svoboda and B.A. Fuchs). Integrated Drought Management Programme (IDMP), Integrated Drought Management Tools and Guidelines Series 2. Geneva.

Zargar, A., Sadiq, R., Naser, B. and Khan, F.I. (2011). A review of drought indices. Environmental Reviews. 19, 333-349. 